\title{
Sexual Behaviour among Students in a Tertiary Educational Institution in Southeast Nigeria
}

\author{
Adinma Joseph Ifeanyi Brian ${ }^{*}$, Osita Umeononihu' ${ }^{1}$, Adinma Dolly Echendu², \\ Nkemakolam Eke $^{3}$ \\ ${ }^{1}$ Department of Obstetrics and Gynaecology, Nnamdi Azikiwe University Teaching Hospital, Nnewi, Nigeria \\ ${ }^{2}$ Department of Community Medicine, Nnamdi Azikiwe University Teaching Hospital, Nnewi, Nigeria \\ ${ }^{3}$ Department of Obstetrics and Gynaecology, Federal Medical Centre, Keffi, Nigeria \\ Email: "brianadinma@yahoo.com
}

Received 31 May 2016; accepted 18 July 2016; published 21 July 2016

Copyright (C) 2016 by authors and Scientific Research Publishing Inc.

This work is licensed under the Creative Commons Attribution International License (CC BY). http://creativecommons.org/licenses/by/4.0/

\section{(c) (i) Open Access}

\begin{abstract}
Background: Sexual behaviour is the manner in which humans experience and express their sexuality. When it is risky, it can lead to untoward health consequences. Objective: The study was undertaking to assess the sexuality pattern of 276 students from a tertiary educational institution in Anambra state of south eastern Nigeria to determine the pattern of risk-behavior among them. Subjects/Methods: This is a cross-sectional questionnaire based study of undergraduates in a tertiary educational institution. Results: Majority of the respondents $190 / 276(68.8 \%)$ are sexually active. Most of the sexually active respondents are unmarried $156(82.1 \%)$ while only $34(17.9 \%)$ were married. A considerable number of the respondents $34(17.9 \%)$ had 2 to 5 sex partners in the past one year while $26(13.7 \%)$ had at least 6 sex partners the past year also. Interestingly, $140(73.7 \%)$ respondents were having sex for pleasure and while only $14(7.4 \%)$ had sex for money. Conclusion: Majority of the undergraduates in this study indulge in premarital sexual intercourse and usually often with multiple partners. This constitutes high risk sexual behavior. Recommendations: Safer-sex sexuality education is recommended for students in tertiary educational institutions to minimize this ugly trend.
\end{abstract}

\section{Keywords}

Sexual Behavior, Youth, Students, Tertiary Institution, Nigeria

\footnotetext{
${ }^{*}$ Corresponding author.
}

How to cite this paper: Brian, A.J.I., Umeononihu, O., Echendu, A.D. and Eke, N. (2016) Sexual Behaviour among Students in a Tertiary Educational Institution in Southeast Nigeria. Advances in Reproductive Sciences, 4, 87-92. 


\section{Introduction}

Sexual behaviour is the manner in which humans experience and express their sexuality. It also means any activity between two persons (solitary) or in a group that induces sexual arousal. The sexual behaviour of an individual is to a large extent a function of the inherited sexual response pattern or the extent of the restraint exerted on the individual by society.

Risky sexual behaviors are sexual behaviors that increase the chance of contacting or transmitting disease or unwanted pregnancy. They include: multiple sexual partners, oral, anal and vaginal sex without protection; using unreliable methods of contraception and inconsistent use of it. It also includes the frequency of changing sexual partners.

The centre for disease control (CDC) defines risky sexual behaviour as that which increases one's risk of contacting sexually transmitted infections and experiencing unwanted pregnancies. They include having sex at an early age, multiple sexual partners, having sex under the influence of alcohol or drugs and unprotected sexual behaviors [1].

The feared consequences of risky sexual behaviors are: sexually transmitted diseases, unwanted pregnancy and sometimes psychological consequences of sexual violence [2]. This study was undertaken amongst students in a tertiary institution to ascertain the risky sexual behaviors amongst them so as to suggest solutions on how to remedy the problem.

\section{Subjects and Method}

This is a self-administered questionnaire-based study conducted among 276 students randomly selected from the various faculties of the two campuses of Nnamdi Azikiwe University-at Awka and Nnewi, in Anambra State of South Eastern Nigeria. Ethical clearance for this study was obtained from the ethics committee of Nnamdi Azikiwe University and Teaching Hospital. A detailed explanation of the questionnaire schedule was made to the students together with the need for them to respond truthfully and honestly, in-spite of the sensitive nature of the questions contained in the questionnaire. Only the students that gave consent following the detailed explanation of the study were interviewed. The questionnaire schedule elicited information from the respondents in respect of their social demographic characteristics—age, sex, marital status and religion; sexual activity patternwhether or not the respondent were sexually active and number of sexual partner over the past years; and reasons for engaging in sexual intercourse-whether for procreation, pleasure, money, to please partner, to obtain favour, to express love or all of the above

A total of 300 questionnaires were administered but only 276 were found usable after editing. The completed questionnaires were keyed into the system and analyzed using SPSS version 17.0. Statistical relationships between variables were explored using chi-square test and a p value of $<0.05$ at a $95 \%$ confidence interval was considered to be significant for all statistical comparisons.

\section{Results}

The Distribution By the socio-demographic characteristics of the Respondents is shown in Table 1.

The mean age of the respondents was 23.1 years. Majority of the respondents came within the age range of 20 - 24 years with a summation of frequency of $(\Sigma f x) 3608$ - $164(59.4 \%)$ while the least age group was 15 - 19 years-32 (11.6\%) and had a summation of frequency of $(\Sigma f x) 544$. There were $168(60.9 \%)$ males and 108 (39.1\%) females. The majority of the respondents, 242 (87.7\%) were single while only 34 (12.3\%) were married. Most of the respondents 266 (96.4\%) were Christians

The distribution by the pattern of sexuality of the respondents as shown in Table 2 indicate that as high as 190 (68.8\%) were sexually active, while 82 (29.7\%) were not. Sexual debut occurred amongst respondents within all the age ranges 1 - 5 to 20 - 25, but occurred most commonly within the age range of 16 - 20 years118 (62.1\%). Sexual debut even occurred within the age range of 1 - 5 years-4 (2.1\%). Thirty five (36.8\%) of the respondents had had only one sexual partner within the past one year, While 34 (35.8\%) had had up to 2 - 5 partners. As high as 18 (19.00\%) respondents had had 6 - 10 sex partners within the past year, while 8 (8.4\%) had had more than 10 or more.

Figure 1 shows the reason given by the respondents for sexual intercourse. The commonest reason given was for pleasure 140 (73.7\%) other reason given include please a partner 18 (9.5\%); for money 14 (7.4\%) for procreation $8(4.2 \%)$; to obtain favour $6(3.2 \%)$ and to express love $2(1.1 \%)$. Two of the respondents give all the 
Table 1. Distribution by socio-demographic characteristics of the respondents.

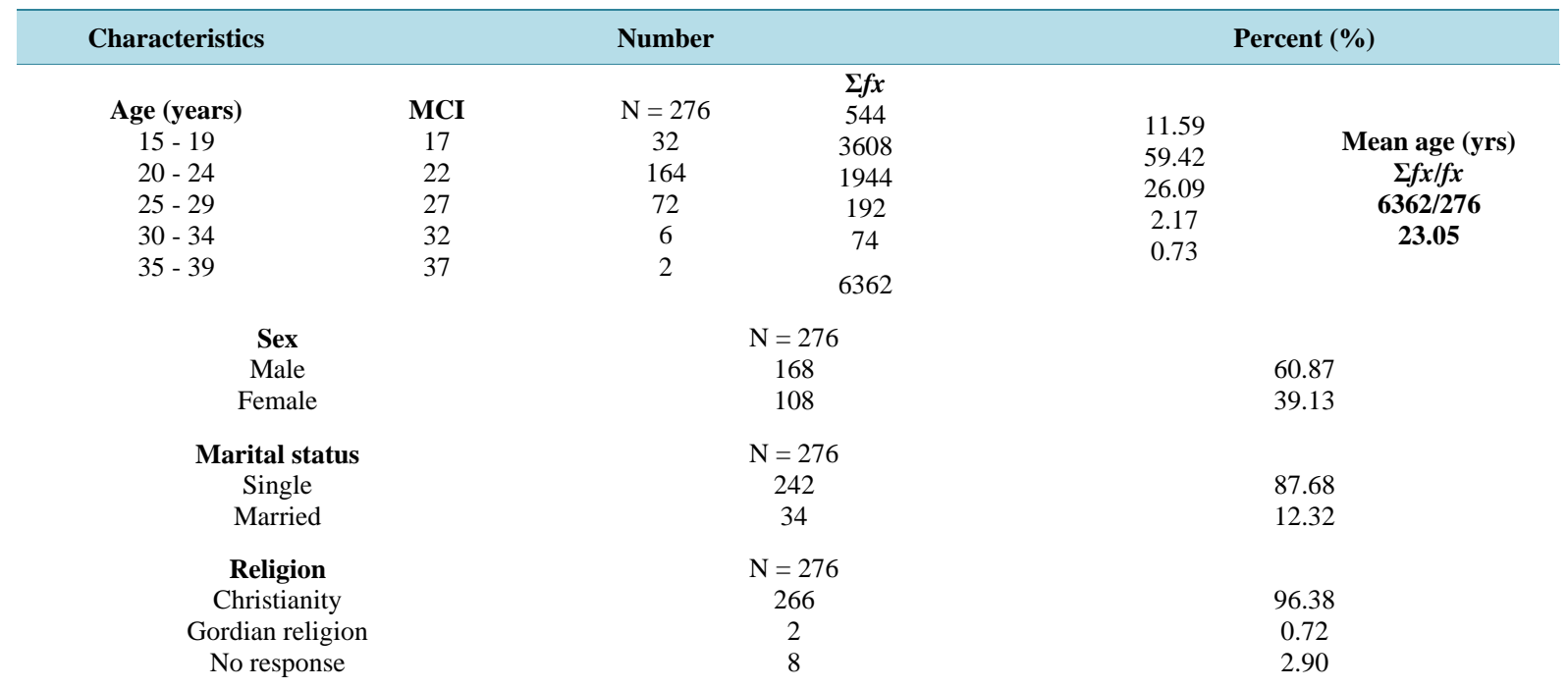

Key: MCI = mid class interval, $\mathrm{N}=$ number of frequency.

Table 2. Distribution by pattern of sexuality.

\begin{tabular}{|c|c|c|c|c|c|}
\hline \multicolumn{2}{|l|}{ Characteristic } & \multicolumn{2}{|c|}{ Number } & \multicolumn{2}{|c|}{ Percent (\%) } \\
\hline \multicolumn{2}{|l|}{ Sexually active } & \multicolumn{2}{|c|}{$\mathrm{N}=276$} & \\
\hline \multicolumn{2}{|l|}{ Yes } & \multicolumn{2}{|c|}{190} & \multicolumn{2}{|c|}{68.84} \\
\hline \multicolumn{2}{|l|}{ No } & \multicolumn{2}{|c|}{82} & \multicolumn{2}{|c|}{29.71} \\
\hline \multicolumn{2}{|l|}{ No response } & \multicolumn{2}{|c|}{4} & \multicolumn{2}{|c|}{1.45} \\
\hline Age at first intercourse & MCI & $\mathrm{N}=190$ & $\Sigma f x$ & & Mean \\
\hline $1-5$ & 3 & 4 & 12 & 2.11 & \\
\hline $6-10$ & 8 & 10 & 80 & 5.26 & \\
\hline $11-15$ & 13 & 38 & 494 & 20.00 & $\Sigma f x / \Sigma f$ \\
\hline $16-20$ & 18 & 118 & 2124 & 62.11 & $=3170 / 190$ \\
\hline \multirow[t]{2}{*}{$21-25$} & 23 & 20 & 460 & 10.53 & $=16.68$ years \\
\hline & & 190 & 3170 & & \\
\hline Sex partners in past & & \multicolumn{2}{|c|}{$\mathrm{N}=95$} & & \\
\hline Only 1 & & \multicolumn{2}{|c|}{35} & \multicolumn{2}{|c|}{36.84} \\
\hline $2-5$ & & \multicolumn{2}{|c|}{34} & \multicolumn{2}{|c|}{35.79} \\
\hline $6-10$ & & \multicolumn{2}{|c|}{18} & \multicolumn{2}{|c|}{18.95} \\
\hline$\geq 10$ & & \multicolumn{2}{|c|}{8} & \multicolumn{2}{|c|}{8.42} \\
\hline
\end{tabular}

reasons for engaging in sexual intercourse.

\section{Discussion}

The ages of the majority 164 (59.4\%) of the respondents in this study fall within the range of 20 - 24 years, which corresponds with the World Health Organization's (WHO's) definition of youth [3]. In addition up to 32 (11.6\%) of the respondents were age between 15 and 19 years, designated as adolescence [3]. The adolescence age represents a transition from childhood to adulthood and it is characterized by physical, sexual and emotional changes and an inherent tendency to explore-particularly sexuality with attendant high-risk sexual behaviors that may result in unwanted pregnancy with unsafe abortion and its complications; and sexually transmitted infections including HIV/AID. The combination of the youths and adolescents in the study totaling 196 (71.0\%) represents a highly vulnerable segment and probably also constitute an integral part of the 242 number of unmarried respondents.

In this study, 190 (68.8\%) respondents are sexually active, and most of these are constituted of adolescents and youths who form the majority of unmarried respondents. This finding is in agreement with previous reports that indicates the high sexual activity of adolescents and youths [4]. 


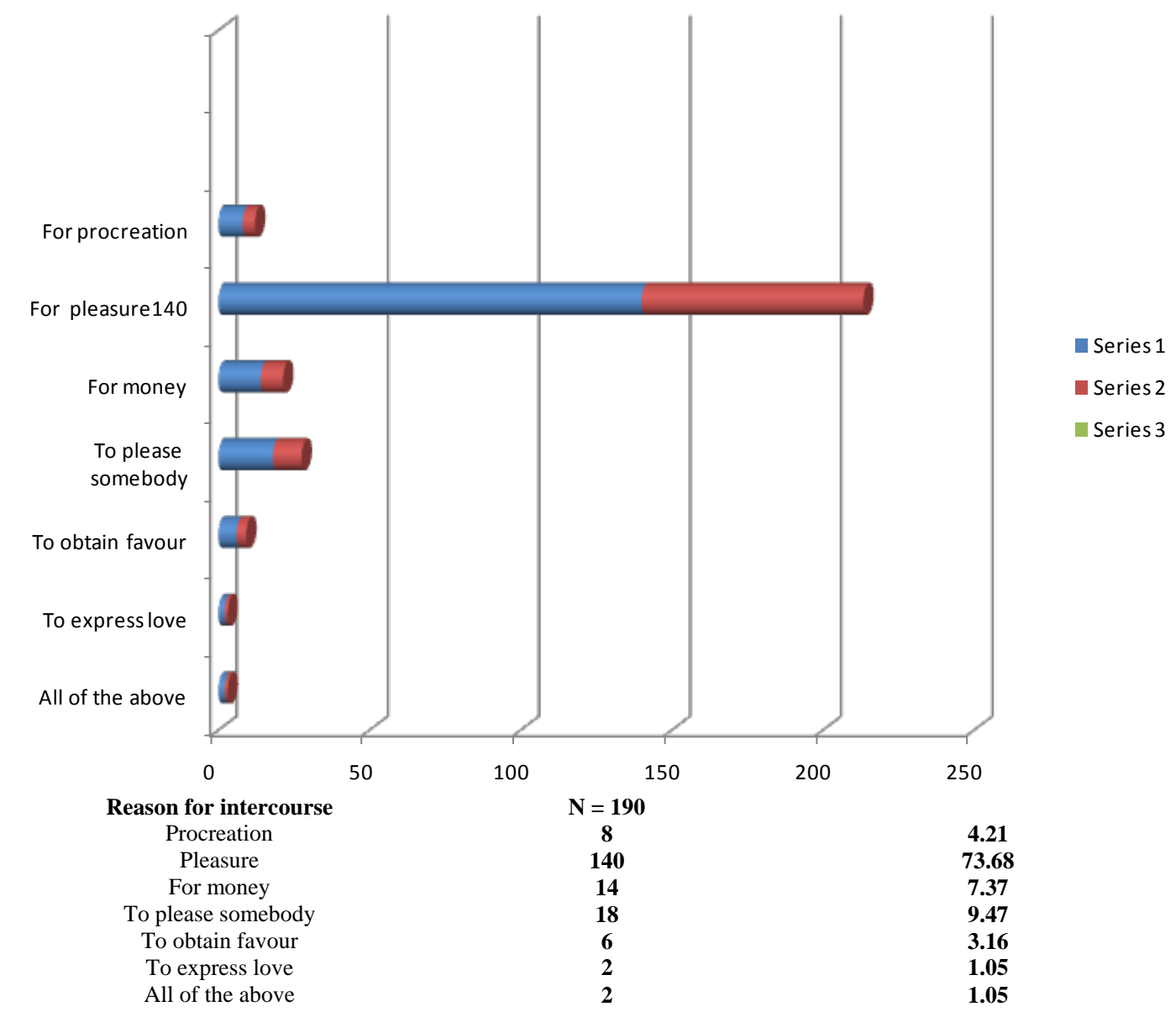

Figure 1. Distribution by reasons for sexual intercourse.

The $68.8 \%$ sexually active respondents shown in this study is higher than that of the report of the 2013 Nigeria National Demographic and Health Survey (NDHS) which shows that $48.9 \%$ of adolescents are sexually active [5]. This may probably be due to the fact that the NDHS data is purely on adolescents while the respondents in this study were blend of adolescents and the youth. It is worrisome to note that only 35 (36.8\%) of the sexually active respondents in our study had only one sexual partner in the past one year. The remaining $63.2 \%$ majority were having sex with multiple partners, with as high as $27.4 \%$ having sexual intercourse with as many as six or more partners. This finding is comparable to the report from a study conducted at Ilorin Nigeria which showed that $62.3 \%$ of tertiary students studied, had more than one sex partner in the preceding two months [6]. The reason for multiple sexual partners may not be unconnected to the fact that adolescents and young person often engage in sexual experimentation and are often times ignorant of the associated negative consequences. Evidence to this can be adduced in this study from the fact that as high as 140 (73.7\%) of the respondents indulge in sexual activity for "pleasure", a situation which is even more worrisome. The $63.2 \%$ of the sexually active respondents with multiple sexual partners observed in this study is higher than $51.7 \%$ reported by Hazzaz et al. [7] in Kano and 56.2\% reported by Sabitu et al. [8] in Minna both in Northern Nigeria, thereby suggesting regional differences in multiple sexual partnering in Nigeria. It further more compares to the findings of Owoaje et al. [9] who reported multiple sexual partnering in $58.2 \%$ of street youths in south western Nigeria.

The inference from this therefore is that the sexuality pattern amongst students in the campuses of higher educational institutions may not be different from what is obtained on the streets, and may even be worse.

Sexual intercourse with multiple partners, particularly when unprotected is indeed a high risk behavior that places the individual at increased danger of sexually transmitted infections and unwanted pregnancy!

This is even more glaring for adolescents and youth in higher educational institutions characterized to have a high rate of sexual activity with relatively low contraceptive and condom usage [10]-[12]. 
Commonly encountered sexual transmitted infection may be asymptomatic, although often times are symptomatic. Symptomatic STIs can be ulcerative and non-ulcerative. Common ulcerative Sexually Transmitted Infection particularly in the tropic include-Herpes genitalis, Syphilis, Chancroid, Granuloma Inguinale, and Lymphogranuloma Venerum [13] [14]. Non-ulcerative sexually transmitted infection usually present with urethritis or vaginal discharge, as in infections from organism such as Neisseria gonorrhoea, Chlamydia trachomatis, Mycoplasma genitalium, Trichomonas vaginalis and Ureaplasmaurealiticum [15].

Another risky sexual behavior found in this study population is early sexual debut. The mean age of sexual debut in this study is 16.7 years (Table 2). This compares to the 17 years for the never married and 18 years for the married reported by Isiugo et al. in Cross River and Oyo states of southern Nigeria [16]. However, unlike the Cross River and Oyo States study which is a household survey, this is an institutional survey. This further suggests that sexual behaviour of adolescents is similar whether they are at home, in the school or in the street corners. It also compares to the 16.4 and 19.0 years for female and male students respectively reported from Minna north central Nigeria [17]. Unlike the Minna study however, ours did not seek for male and female ages at sexual debut differently.

It is interesting to note that sexual debut occurred at all the age-ranges in this study, starting from $4(2.1 \%)$ at age range 1 - 5, and with the majority experiencing sexual debut at the age-range of 16 - 20 years, 118 (62.1\%). The implication of this is that age consideration should not constitute a barrier to extending sexuality education to people.

\section{Conclusion and Recommendation}

This study reviews a high rate of sexual activity, $68.8 \%$, among the students surveyed in the tertiary educational institution. Their age at sexual debut spanned through the age-range from 1 - 5 years to 20 - 25 years, and majority of them $62.3 \%$ had multiple sexual partners with a considerable number of $27.4 \%$ having as many as six or more sexual partners over the past one year. These constitute a high risk sexual behaviour pattern that would predispose the students to unwanted pregnancy and sexually transmitted infection.

The need to integrate sexuality education especially safe sex practices into a comprehensive reproductive health advocacy program targeted at higher educational institutions in Nigeria, even also including programs for out of school youths has become critical, if the present unsalutary sex behavior pattern amongst adolescents and youth in Nigeria is to be reversed. Such reproductive health program should be planned to span through the educational chain with the allocation of the relevant reproductive health information to the various levels of the educational chain, starting with the basic information on anatomy and physiology of the reproductive system at the primary level, to issues of safe sexuality including family planning and sexually transmitted infection at the secondary and tertiary educational level. Advocacy tools should include policies that harness the curriculum at both primary and secondary education, reproductive health enlightenment lectures at schools and also in the prints and electronic media. The social media has become an increasingly popular source of information for youths and adolescents and should therefore be explored to ensure that consistent and correct information on sexuality and reproductive health generally is posted to guide young persons towards making correct and informed reproductive health decisions.

\section{Acknowledgements}

The authors are grateful to South East Nigeria (SE-PAC-Net) for sponsoring the conduct of this research.

\section{References}

[1] Centres for Disease Control and Prevention (2010) Youth Risk Behavior Surveillance. USA 2009, MMWR 39; No. SS-5: 1-42.

[2] Emma-Slaymaker, Walker, N.H., Zaba, B. and Collumbian, M. (2009) Unsafe Sex in; Global Health Risks, Mortality and Burden of Disease Attributable to Selected Major Risks. WHO, Geneva, 1178-1254.

[3] Umeononihu, O.S. (2012) Adolescent Reproductive Health in Nigeria, the Role of the Family. WOSSRI News, 11, 1-4.

[4] Centres for Disease Control and Prevention (2005) Youth Risk Behaviour, Surveillance USA 2005. Summaries 55 (SS-5).

[5] National Population Commission (NPC) Nigeria and ORC Macro (2009) Nigeria Demographic and Health Survey 2009. Calverton. 
[6] Fawole, A.O., Ogunkan, D.V. and Adegoke, G.S. (2011) Sexual Behaviour and Perception of HIV/AIDS in Nigerian Tertiary Institutions: University of Ilorin a Case Study. Global Journal of Human Social Science, 11, 1.

[7] Hazzaz, M.D., Bin, K., Zubairu, I. and Isa, S.A. (2005) Sexual Behavior among Students in Tertiary Institutions in Kano Northern Nigeria. Journal of Community Health and Primary Care, 16, 17-22.

[8] Sabitu, K., Iliyasu, Z. and Baba, S.E. (2007) Sexual behavior and predictors of condom use among students of a Nigerian tertiary institution. Nigerian Journal of Medicine, 16, 338-343.

[9] Owoaja, E.T. and Uchendo, O.C. (2009) Sexual Risk Behaviour of Street Youths in South West Nigeria. East African Journal of Public Health, 6, 274-279.

[10] Adinma, J.I.B., Okeke, A.O., Agbai, A.O. and Okoro, J.M. (1999) Contraception in Teenage Nigerian School Girls. Advances in Contraception, 15, 283-291. http://dx.doi.org/10.1023/A:1006732222373

[11] Adinma, J.I.B. and Okeke, A.O. (1995) Contraception Awareness and Practice among Nigeria Tertiary School Girls. West African Journal of Medicine, 14, 34-37.

[12] Chukwuma, D., Anthony, I., Kelvin, C.D., Kelechi, A.U., Irene, A.M., Chima, A.E. and Uche, R.O. (2005) Sexual Behavior, Contraceptive Knowledge and Use among Female Undergraduate in Imo State Nigeria. American Journal of Medical Science and Medicine, 3, 61-66.

[13] Okonko, I.O., Akinpelu, A.O. and Okerentugba, P.O. (2012) Prevalence of Sexually Transmitted Infections among Attendees of ARFH in Ibadan Southwestern Nigeria. Middle Eastern Journal of Scientific Research, 11, $24-31$.

[14] Robyn, N.F. and Kimberly, A.W. (2014) Clinical Update in Sexually Transmitted Diseases. Cleveland Clinic Journal of Medicine, 81, 91-101.

[15] Holmes, K., Sparling, P., Stamm, W., Piot, P., Wasserheit, J., Corey, L. and Cohen, M. (2007) Sexually Transmitted Diseases. 4th Edition, McGraw-Hill Professional Publishing, New York.

[16] Isiugo-Abanihe, U.C., Erinosho, O., Ushie, B., Aderinto, A., Sunmola, G. and Joseph, R. (2012) Age of Sexual Debut and Patterns of Sexual Behavior in Two Local Government Areas in Southern Nigeria. African Journal of Reproductive Health, 16, 81-94.

[17] Sabitu, K., Iliasu, Z. and Baba, S.E. (2007) Sexual Behavior and Predictors of Condom Use among Students of a Nigerian Tertiary Institution. Nigerian Journal of Medicine, 16, 338-343.

\section{Submit or recommend next manuscript to SCIRP and we will provide best service for you:}

Accepting pre-submission inquiries through Email, Facebook, LinkedIn, Twitter, etc.

A wide selection of journals (inclusive of 9 subjects, more than 200 journals)

Providing 24-hour high-quality service

User-friendly online submission system

Fair and swift peer-review system

Efficient typesetting and proofreading procedure

Display of the result of downloads and visits, as well as the number of cited articles

Maximum dissemination of your research work

Submit your manuscript at: http://papersubmission.scirp.org/ 